\title{
Takotsubo Cardiomyopathy Complicated with Left Ventricle Outflow Tract Obstruction Secundary to Mental Stress. Case Report
}

\begin{abstract}
Summary
We report the case of a 64-year-old woman with a history of chronic exposure to wood smoke, systemic arterial hypertension with prior treatment, and an acute event of psychic stress, 7 days prior to admission. Her symptoms began as a precordial pain associated with an ST segment elevation in her electrocardiograph, as well as a Troponine elevation. Thrombolysis was performed without reperfusion criteria, which afterwards developed into acute heart failure. Afterwards, she was sent to the Cardiology Unit of our hospital where we performed coronary angiography and ventriculography, which demonstrated intense apical dyskinesia and normal coronary arteries. We also found a left ventricle outflow tract obstruction through echocardiography. Due to the remission of the outflow tract obstruction, apical dyskinesia and acute heart failure, we concluded that our diagnosis was a case of Takotsubo cardiomyopathy.
\end{abstract}

Keywords: Takotsubo cardiomyopathy; Apical dyskinesia; Acute heart failure; Left ventricle outflow tract obstruction

Research Article
Volume 10 Issue 2 - 2017
Luis Delgadlo-Leal1* and Reynaldo Perez
Delgado
Cardiólogo Hemodinamista, Centenario Hospital Miguel
Hidalgo, México
*Corresponding author: Luis Delgado-Leal, Cardiólogo
Hemodinamista, Centenario Hospital Miguel Hidalgo,
Aguascalientes, México, Email: guicho.ags@hotmail.com
Received: September 26, 2017 | Published: November 24,
2017

\section{Introduction}

Takotsubo Syndrome is an acute heart failure that affects Predominantly posmenopausal women. It is similar to acute coronary syndromes with ST segment elevations, therefore, it's estimated that $1 \%$ to $2 \%$ of all acute coronary syndromes are Takotsubo cardiomyopathy. There's also a relation to physical and psychological stress factors, without an exact physiopathology [1]. A previous RETAKO trial, observed that more than half of their patients had some type of psychological stress [2]. Takotsubo cardiomyopathy etiology has been divided between a primary and secondary form, with the former being caused by physical and psychic stress, as well an idiopathic cause. This group has a better long term prognosis when compared to the secondary form, which includes sepsis, intracranial hemorrhage, cerebrovascular disease, recent surgery, or critical illness [3].

The hyperkinetic characteristics of the right ventricle's function with cardiogenic shock can reflect an adaptative state due to a low left ventricle preload [4]. Kosuge's electrographic criteria is used to differentiate between an acute infarction with an ST segment elevation and anterior topography with Tokotsubo cardiomyopathy, which includes an ST depression at the aVR lead with an absence of an ST elevation at the V1 lead [5].

\section{Case Presentation}

64 year old female with the following history: Aguascalientes resident, married, house wife, chronic exposure to wood smoke, systemic arterial hypertension. Intense psychic stress during the week prior to admission. No chronic or degenerative diseases.

\section{Problem on Admision}

The patient begins with precordial pain associated with an ST segment as shown in electrocardiography, of an anterior localization. After admittance, the emergency team proceeds to start thrombolysis without reperfusion criteria, which evolves to acute heart failure. Afterwards she's transferred to our cardiology unit, where the patient undergoes coronariography and ventriculography studies, with evidence of normal coronary arteries and Intense apical dyskinesia, the patient also undergoes an echocardiography which shows significant outflow tract obstruction of the left ventricle.

\section{Physical Exploration}

Patient is alert, neck with jugular ingurgitation, thorax with bilateral subcreptitant rales, precordium with double apical impulse, with an apex displacement towards the sixth intercostal space, systolic murmur with its epicenter at the inferior region of the left parasternal border that increases with the pressure phase of Valsalva maneuver. Abdomen with no clinical signs, extremities without edema, symmetric distal pulse with normal amplitude.

\section{Lab Results (At Hospital Admittance)}

Glucose $123 \mathrm{mg} / \mathrm{dl}$, urea $53 \mathrm{mg} / \mathrm{dl}$, creatinine, $0.7 \mathrm{mg} / \mathrm{dl}$, sodium $140 \mathrm{mmol} / \mathrm{l}$, potasium $3.8 \mathrm{mmol} / \mathrm{l}$, chloride $104 \mathrm{mmol} / \mathrm{l}$, leucocytes 18000, hemoglobin $13 \mathrm{~g} / \mathrm{dl}$, platelets, 182 000, I.N.R 1.39, CPKMB 1.8 U/L, Troponine I $9.4 \mathrm{ng} / \mathrm{ml}$ (Figure 1).

\section{Transthoracic Echocardiogram at Admittance}

After admittance, the patient underwent a transthoracic 
echocardiogram where we observed a left ventricle outflow tract gradient of $91 \mathrm{mmHg}$, as well as apical dyskinesia (Figure $2 \& 3$ ).

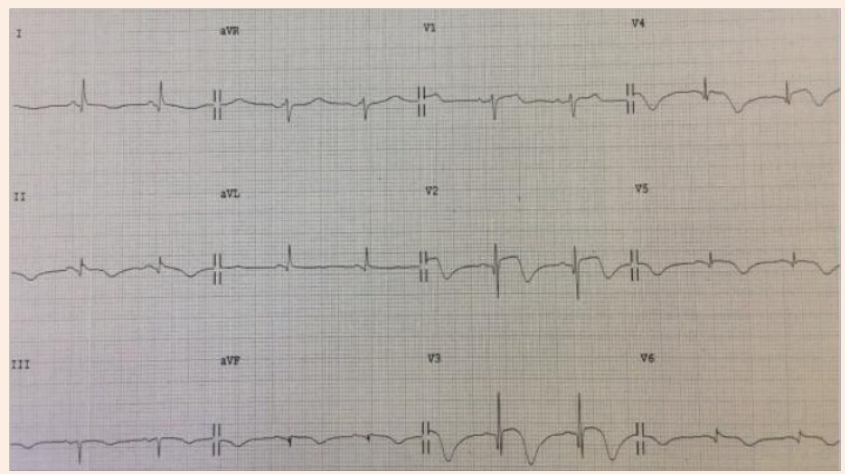

Figure 1: 12 Lead electrocardiograph with an ST elevation from V2 to V6, with an asymmetric inversion of T wave branches [1].

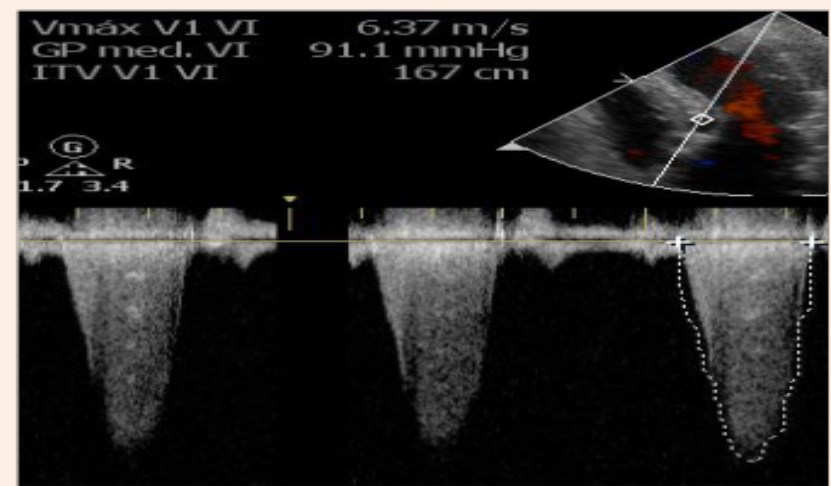

Figure 2: Left ventricle outflow gradient of $91 \mathrm{mmHg}$ (Taken at admittance).

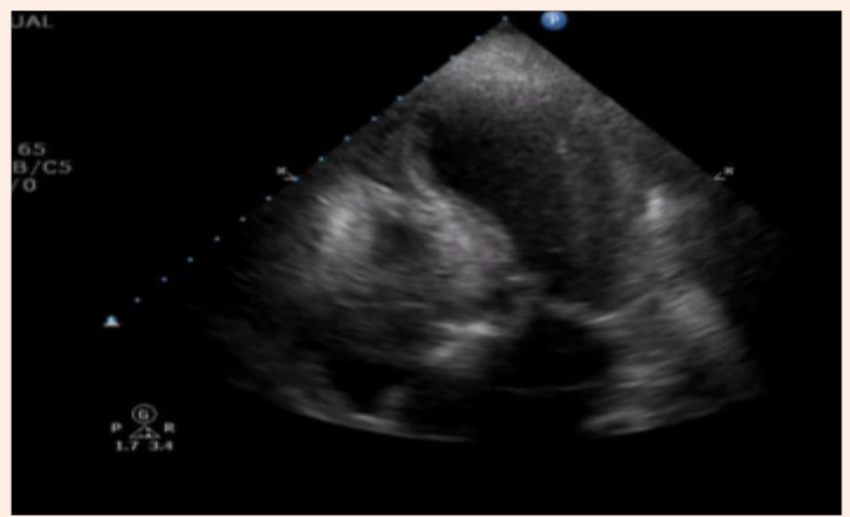

Figure 3: Left ventricle apical dyskinesia as seen with a 4 chamber apical view.

\section{Coronariography}

Due to the clinical status of the patient, electrocardiography signs and biomarkers, we decided to do a coronariography study, in which there was no evidence of angiographic injuries.
Ventriculography also highlighted an intense apical diskinesia. After observing coronariography results, our differential diagnosis was of myocarditis versus Takotsubo myocardiopathy. After magnetic resonance imaging, we found a late highlight absence of the left ventricle at T2, as well as a short axis apical hyperintensity, such findings suggest Takotsubo cardiomyopathy, which also excluded miocarditis (Figure 4).

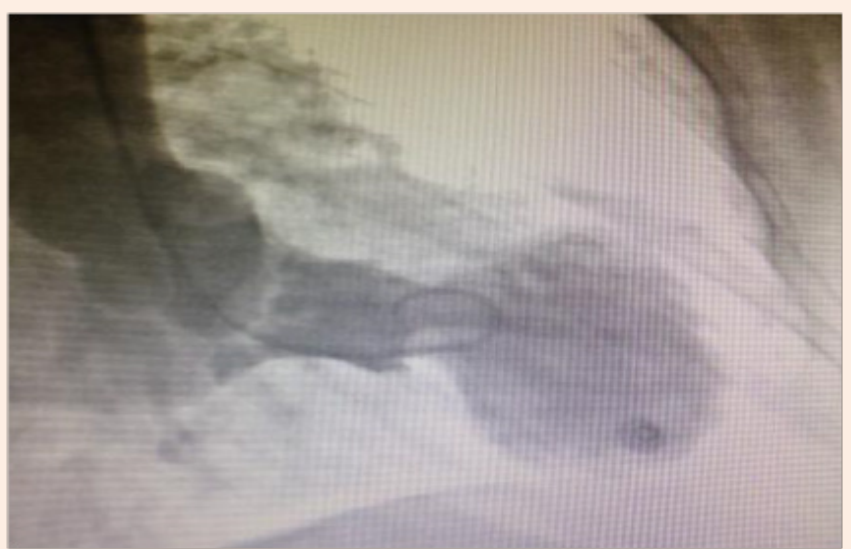

Figure 4: Left anterior oblique ventriculography with important apical dyskinesia.

\section{Magnetic Resonance Imaging}

Four chamber apical cut at T2 phase where we observe an absence of a late highlight of the left ventricle (Figure 5). Short axis apical cut at black sequence phase where we observe a hyperintense highlight at the apical endocardium (Figure 6).

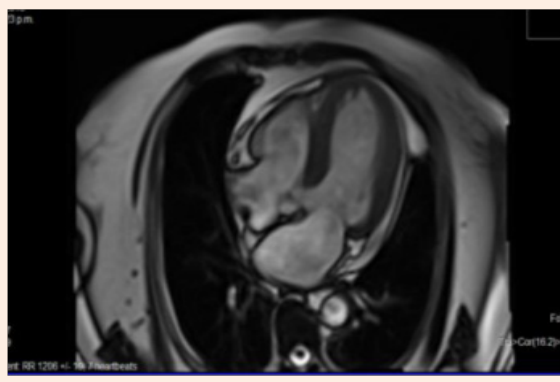

Figure 5

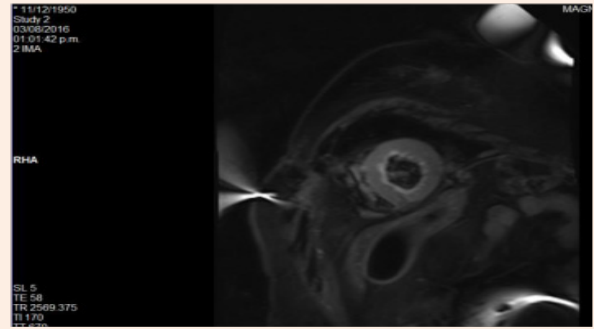

Figure 6 


\section{Clinical Evolution}

After our final test results, we began treatment for acute heart failure with diuretics, inotropics, vasodilators, did not require ventricular assist devices post-treatment improvement in one week. Our final diagnosis was of Takotsubo cardiomyopathy complicated with a dynamic obstruction of the outflow tract of the left ventricle, follow up was carried out at the outpatient cardiology clinic, with a two month follow up echocardiogram which showed gradient resolve at the outflow tract, therefore backing up our diagnosis.

\section{Discussion}

In this case, the main differential diagnosis was an acute coronary syndrome which was excluded when normal coronary arteries were found. Subsequently, a protocol for MINOCA (Myocardial Infarction With Non Obstructive Coronary Arteries) was performed. In the ventriculography an intense apical dyskinesia was observed, thus suspecting the syndrome of takotsubo which finally corraborated through magnetic resonance due to the absence of delayed enhancement with gadolinium and apical edema. Finally, we concluded that the trigger was a psychic stress event that the patient had attended the days prior to admission.

\section{Conclusion}

This particular case showed an interesting behavior of Takotsubo disease that mimicked an acute coronary syndrome, insomuch initial treatment was of thrombolysis. Despite this, after initial studies and usage of Mayo Criteria, we concluded that the diagnosis was of Takotsubo cardiomyopathy, complicated with a dynamic obstruction of the left ventricle outflow tract, a disease described in current literature as rare and transitory, just as presented in our case study.

\section{References}

1. Templin C, Napp LC, Ghadri JR (2016) Takotsubo Syndrome Underdiagnosed, Underestimated, but Understood? JACC 67(16): 1937-1940.

2. Núñez Gil I, Andrés M, Almendro D, Sionis A, Martín A, et al. (2015) Characterization of Tako-tsubo Cardiomyopathy in Spain: Results from the RETAKO National Registry. Rev Esp Cardiol (Engl Ed) 68(6): 505-512.

3. Thomas S, Holger T, Ingo Eitel (2006) Prognosis in Patients With Takotsubo Cardiomyopathy. JACC: Heart Failure 4(6): 519-520.

4. Rodolfo Citro (2014) Jorge Salerno Uriarte, MD. Complexity of Assessmente an Management of Tako-Tsubo Cardiomiopathy. JACC 7(7): 741-742.

5. Núñez-Gil IJ, Luaces M, Garcia-Rubira JC, Zamorano J (2010) Electrocardiographic Criteria in Takotsubo Cardiomiopathy and Race Differences Asian versus Caucasians. JACC 56(17): 1433-1434. 